\title{
Functional connectivity in the retina at the resolution of photoreceptors
}

\author{
Greg D. Field ${ }^{1,{ }^{*}}$, Jeffrey L. Gauthier ${ }^{1,{ }^{*}}$, Alexander Sher ${ }^{2,},{ }^{*}$ Martin Greschner ${ }^{1}$, Timothy \\ Machado $^{1}$, Lauren H. Jepson ${ }^{1}$, Jonathon Shlens ${ }^{1}$, Deborah E. Gunning ${ }^{3}$, Keith Mathieson ${ }^{3}$, \\ Wladyslaw Dabrowski ${ }^{4}$, Liam Paninski ${ }^{5}$, Alan M. Litke ${ }^{2}$, and E.J. Chichilnisky ${ }^{1}$
}

${ }^{1}$ Systems Neurobiology Laboratory, Salk Institute for Biological Studies, La Jolla, CA ${ }^{2}$ Santa Cruz Institute for Particle Physics, University of California, Santa Cruz, CA ${ }^{3}$ Department of Physics and Astronomy, University of Glasgow, Glasgow, UK ${ }^{4}$ Faculty of Physics and Applied Computer Science, AGH University of Science and Technology, 23 30-059, Krakow, Poland 5 Department of Statistics and Center for Theoretical Neuroscience, Columbia University, New York, NY

\section{Abstract}

To understand a neural circuit requires knowing its connectivity. This paper reports measurements of functional connectivity between the input and ouput layers of the retina at single cell resolution and its implications for color vision. Multi-electrode technology was employed to record simultaneously from complete populations of the retinal ganglion cell types (midget, parasol, small bistratified) that transmit high-resolution visual signals to the brain. Fine-grained visual stimulation was used to identify the location, type and strength of the functional input of each cone photoreceptor to each ganglion cell. The populations of ON and OFF midget and parasol cells each sampled the complete population of long and middle wavelength sensitive cones. However, only OFF midget cells frequently received strong input from short wavelength sensitive cones. ON and OFF midget cells exhibited a small non-random tendency to selectively sample from either long or middle wavelength sensitive cones, to a degree not explained by clumping in the cone mosaic. These measurements reveal computations in a neural circuit at the elementary resolution of individual neurons.

Color vision requires neural circuitry to compare signals from spectrally distinct cone types. For example, the signature of primate color vision - red-green and blue-yellow color opponency - implies that neural circuits pit signals from different cone types against one another. However, the pattern of connectivity between the (L)ong, (M)iddle, and (S)hort

Users may view, print, copy, download and text and data- mine the content in such documents, for the purposes of academic research, subject always to the full Conditions of use: http://www.nature.com/authors/editorial_policies/license.html\#terms

Contact: E.J. Chichilnisky, Systems Neurobiology, The Salk Institute, 10010 North Torrey Pines Road, La Jolla, CA 92037, USA. ej@salk.edu, phone: (858) 453-4100 x1286.

*Equal contributions

Author Contributions: G.D.F., J.L.G., A.S., and E.J.C. conceived the experiments. G.D.F., J.L.G., A.S., M.G., J.S., and E.J.C. performed the electrophysiological experiments. G.D.F, J.L.G., A.S., M.G., T.A.M., and L.P., analyzed the data. A.S., D.E.G., K.M., W.D., A.M.L. provided and supported the large-scale multielectrode array system. G.D.F. and E.J.C. wrote the manuscript. 
wavelength sensitive cones and various retinal ganglion cell (RGC) types, which determines how color signals are transmitted in parallel pathways to the brain, remains incompletely understood ${ }^{1-9}$. To probe the circuitry for color vision more fully, the pattern of connectivity between the full lattice of cone photoreceptors and complete populations of RGCs of several types was measured in primate retina.

Hundreds of RGCs were simultaneously recorded in the peripheral macaque retina using large-scale electrophysiological recordings ${ }^{10}{ }^{12}$. The light responses of each cell were characterized by computing the spike-triggered average (STA) of a spatio-temporal white noise stimulus (see Methods). From the STA, several features of light response were identified, including the spatial receptive field (RF) and the response time course. Classification based on these properties was used to identify functionally distinct RGC classes (Fig. 1a, center). The RFs of each cell class formed a regular mosaic covering the region of retina recorded ${ }^{12}{ }^{15}$. This revealed that each functionally defined cell class corresponded to one RGC type, because the dendrites of each RGC type uniformly tile the retinal surface ${ }^{16},{ }^{17}$. Density and light response properties were used to identify the ON and OFF midget, ON and OFF parasol, and small bistratified cell types, which collectively account for $\sim 75 \%$ of RGCs ${ }^{5}$. In many cases, RF mosaics exhibited few or no gaps, indicating that nearly every cell was recorded.

To resolve the fine structure of RFs, stimuli with 10 -fold smaller pixels $(5 \times 5 \mu \mathrm{m})$ were used. At this resolution, RFs did not conform to the smooth Gaussian approximation used in Fig. 1a (center) and in previous studies ${ }^{18}$. Instead, each RF was composed of punctate islands of light sensitivity (Fig. 1a, flanking). The separation between islands was roughly equal to the spacing of the cone lattice, consistent with the idea that each island reflected the contribution of a single cone ${ }^{10},{ }^{19}$. To test this hypothesis, locations of islands were compared to photographs of cone outer segments labeled with peanut agglutinin; a close alignment was observed (Fig. 1b, see Supplementary Methods).

The spectral type of each cone -- (L)ong, (M)iddle, or (S)hort wavelength sensitive -- was identified using the relative magnitudes of the three display primaries in the STA at its location (Fig. 2a). These values, accumulated across all cones in a recording, formed three distinct clusters (Fig. 2b) aligned with the spectral sensitivities of the macaque cones (colored lines) ${ }^{20}$. S cones were easily identifiable, $\mathrm{L}$ and $\mathrm{M}$ cones were somewhat less so (Fig. 2b,c) because of their overlapping spectral sensitivities.

The full cone mosaic was visualized by pooling information from all recorded RGCs. This was accomplished by fitting the RFs of all RGCs with a model in which each RF is approximated by a weighted sum of Gaussian functions centered on the locations of cones (see Supplementary Methods). This approach revealed nearly complete cone mosaics (Fig. $2 \mathrm{~d}, \mathrm{e}$ ). The relative frequencies of $\mathrm{L}, \mathrm{M}$ and $\mathrm{S}$ cones were in a ratio of roughly 8:4:1 (average of 6 data sets) ${ }^{21}$.

The functional connectivity between each RGC and the cones within its RF was summarized by assigning an input strength to each cone, equal to the weight in the model fit derived from the STA (see Supplementary Methods). This permitted well-constrained estimation of 
the inputs of weak cones, including those in the RF surround (Fig. 2g), because cone locations were robustly identified using data from multiple cells. The RF of each RGC was summarized graphically with a collection of radiating lines connecting to cones: the thickness of each line is proportional to the weight, white (black) lines represent the center (surround) of the RF (Fig. 2h). This representation was used to visualize several complete mosaics of RGCs receiving input from a complete mosaic of cones (Fig. 3). A total of 1,961 RGCs connecting to a total of 17,380 cones in 7 preparations were examined.

These connectivity diagrams provide insight into the specificity of $\mathrm{L}, \mathrm{M}$ and $\mathrm{S}$ cone inputs to the RGC types mediating high-resolution vision and color vision. This specificity has been a source of controversy in previous work (see Supplementary Discussion).

Previous studies provide conflicting accounts of S cone inputs to midget and parasol cells $1,3,4,6,8,22 \_28$. In the present data OFF midget cells frequently received at least one strong functional $\mathrm{S}$ cone input, whereas ON midget, ON parasol and OFF parasol cells did so much less frequently (e.g. see Fig. 3). At the same time, all four RGC types sampled essentially the entire mosaic of $\mathrm{L}$ and $\mathrm{M}$ cones. For example, in one recording an $\mathrm{ON}$ midget cell received no input from three $\mathrm{S}$ cones located within its RF center (Fig. 4a). Yet, two of these $\mathrm{S}$ cones were sampled by nearby OFF midget cells (Fig. 4b,c). On average, $\mathrm{S}$ cones were strongly sampled by OFF midget cells about five-fold more frequently than by ON midget and parasol cells (Fig. 4d). Additional analysis showed that ON midget cells displayed a tendency to sample weakly from S cones (see Supplementary Methods). The sampling of S cones by OFF midget cells confirms a prediction from anatomical work ${ }^{25}$ : OFF midget bipolar cells contact $\mathrm{S}$ cones in the central retina, therefore, OFF midget RGCs should receive $S$ cone input. The absence of $S$ cone input to parasol cells also confirms recent findings ${ }^{6}$. An important question for future work is whether the $S$ cone signals carried by OFF midget cells contribute to blue-yellow and red-green opponent color vision.

The specificity of $\mathrm{L}$ and $\mathrm{M}$ cone inputs to peripheral midget cells, which is thought to underlie red-green opponent color vision, has also been debated ${ }^{1,8,9,29 \_39}$. One study suggested that midget cells tend to selectively sample from either L or M cones in the RF center, producing red-green color opponency by pitting relatively pure $\mathrm{L}$ or $\mathrm{M}$ cone center signal against a mixture of $\mathrm{L}$ and $\mathrm{M}$ cone signals from the surround ${ }^{2}$. Another study suggested that the RF surround may enhance opponency by sampling predominantly from the cone type less strongly sampled by the center ${ }^{7}$, consistent with previous work ${ }^{3},{ }^{39}$. Yet another study found no evidence for color opponency in peripheral midget cells ${ }^{40}$, suggesting that cone sampling is random in both RF center and surround.

In the present data, a significant fraction of peripheral midget cells exhibited red-green color opponency (Fig. 4h). Opponency was quantified by calculating the relative strengths of the total input from L, M and S cones, obtained with cone-isolating stimuli (see Supplementary Methods) ${ }^{1}$. To examine separately the roles of the RF center and surround in opponency, cones were defined as contributing primarily to the RF center or surround based on the sign of their input and their location (see Supplementary Methods). Interestingly, opponency was often strong in those midget cells that sampled either L or M cones dominantly or exclusively in the RF center, while in the RF surround cone sampling seemed indiscriminate 
(e.g. Fig. 4e-g). These observations are consistent with the hypothesis that sampling bias toward either L or M cones in the RF center mediates opponency. However, across the population of midget cells the purity of cone input to the RF center varied widely (e.g. see Fig. 3c-d), raising the alternative possibility of random sampling in both center and surround.

To test the randomness of $\mathrm{L} / \mathrm{M}$ cone sampling quantitatively, statistical analysis was performed, beginning with cones in the RF center. First, an index of cone input purity was computed for all midget cells in each preparation (Fig. 4i, see Supplementary Methods). The width of the distribution of purity indices quantifies the diversity of cone inputs to recorded cells (Fig. 4j, top). The purity indices were then re-computed after artificially and randomly permuting the identities of $\mathrm{L}$ and $\mathrm{M}$ cones (Fig. $4 \mathrm{j}$, bottom), while preserving all other aspects of the data. If connectivity between $\mathrm{L} / \mathrm{M}$ cones and midget cells were random, then permutation of cone identities would not significantly alter the distribution of purity indices. In fact, the distribution was narrower after permutation, and fewer cells with pure $\mathrm{L}$ or $\mathrm{M}$ cone centers were observed (index values near \pm 1 ). This tendency was statistically significant, and was observed in nearly all of the populations of ON and OFF midget cells examined (Fig. 4k). Although these deviations from random connectivity are small, they imply that the RF centers of midget cells tend to favor inputs from either $\mathrm{L}$ or $\mathrm{M}$ cones, contributing to red-green opponency. In contrast, the same analysis applied to cones in the RF surround yielded results consistent with the hypothesis of random sampling (Fig. 4l).

In principle, the observed tendency toward purity could be produced by clumping in the cone mosaic, i.e. aggregation of cones of the same type. Clumping would increase the proportion of midget cells with centers dominated by one cone type. Evidence for a weak cone clumping was reported in central human retina and peripheral macaque retina ${ }^{41},{ }^{42}$, but the implications for color opponency in midget cells have not been examined experimentally. In the present data, tests for cone clumping on the scale of midget cell RFs suggested a weak tendency toward clumping, in 3 of 7 recordings (see Supplementary Methods). However, clumping alone cannot account for the observed tendency toward purity, because artificial cone mosaics with the same degree of clumping reduced purity (Fig. $4 \mathrm{~m}$ ). Thus, the tendency toward purity indicates that midget cells sample $\mathrm{L}$ and $\mathrm{M}$ cone inputs, through the retinal network, in a selective manner.

Selective sampling could be produced if (1) each midget cell receives inputs from one cone type more frequently than the other, and/or (2) each midget cell weights inputs from one cone type more strongly than the other. Statistical analysis was consistent with both factors. In model (1), the number of cones sampled by each midget cell should be skewed toward one cone type or the other. Therefore, random permutation of L/M cone identities should reduce purity, even if the relative weights of different cone inputs to each cell are ignored by binarizing them. This prediction was confirmed (Fig. 4n). In model (2), the weights on cone inputs to each midget cell should be skewed toward one cone type or the other. Therefore, random permutation of the strength of all the cone inputs within the RF of each midget cell should reduce purity. This prediction was also confirmed (Fig. 4o), though the effect was modest. Control analysis indicated that these findings were not a result of the tapering RF profile of RGCs or clumping in the cone mosaic (data not shown). 
Selective sampling raises questions about the mechanisms by which functional connectivity between cones and RGCs is coordinated. The divergence of the $\mathrm{L}$ and $\mathrm{M}$ cone photopigments in primates is relatively recent ${ }^{43}$, and there is little evidence for segregation of $\mathrm{L}$ and $\mathrm{M}$ cone signals in the retinal circuitry ${ }^{44} \mathrm{~L}$ and $\mathrm{M}$ cones are apparently indistinguishable both anatomically and histochemically. Furthermore, there is only tentative anatomical evidence of differences in retinal circuits carrying $\mathrm{L}$ and $\mathrm{M}$ cone signals ${ }^{35}$, in contrast to the strikingly different pathway that conveys $\mathrm{S}$ cone signals ${ }^{45},{ }^{46}$. Thus, there is no candidate structural basis for selective sampling. In principle, selective sampling could arise from activity-dependent adjustment of synaptic inputs. At the eccentricites recorded, midget bipolar cells usually contact only one cone ${ }^{47}$, providing an opportunity for midget RGCs to selectively sample inputs from bipolar cells carrying signals from one cone type. These bipolar cells could be distinguished by the statistics of their responses to natural scenes ${ }^{48}$. The possibility of such an adaptive mechanism is broadly consistent with recent observations of long-term adaptability in retinal signals ${ }^{49}$ and color vision ${ }^{50}$.

\section{Methods Summary}

Extracellular multi-electrode recordings were obtained from ganglion cells of isolated retinas obtained from macaque monkeys euthanized in other laboratories ${ }^{10}$. Spikes from several hundred cells were segregated offline ${ }^{11}$. Reverse correlation of spike times with white noise checkerboard stimuli focused on the retina were used to obtain RF maps for all cells (Fig. 1). ON and OFF midget and parasol cells and small bistratified cells were classified according to their characteristic light responses and density (Fig. 1) ${ }^{12},{ }^{14},{ }^{15}$. Locations, spectral sensitivity, and input strengths of L, M and $\mathrm{S}$ cones to these cell types were obtained from the fine grained RF maps (Figs. 2,3). To test for selective functional connectivity, the measured spatial arrangement and input strengths of the three cone types to RGCs were compared to artificially modified representations (Fig. 4).

\section{Supplementary Material}

Refer to Web version on PubMed Central for supplementary material.

\section{Acknowledgments}

This work was supported by the Helen Hay Whitney Foundation (G.D.F.), DFG (M.G.), NIH NRSA (NS054519-01) and Chapman Foundation (J.L.G.), Miller Institute for Basic Research in Science, University of CA, Berkeley (J.S.), Polish Ministry of Science and Higher Education (W.D.), Burroughs Wellcome Fund Career Award at Scientific Interface (A.S.), McKnight Foundation (A.M.L. \& E.J.C.), NSF Grant PHY-0750525 (A.M.L.), a Sloan Research Fellowship, and NIH Grant EY13150 (E.J.C). We thank C.K. Hulse for technical assistance; M.I. Grivich, D. Petrusca, A. Grillo, P. Grybos, P. Hottowy, and S. Kachiguine for technical development; H. Fox, M. Taffe, E. Callaway and K. Osborn for providing access to retinas; S. Barry for machining; F. Rieke and T. Sejnowski for providing comments on the manuscript. We thank the San Diego Supercomputer Center and the NSF (Cooperative Agreements 05253071 and 0438741) for large scale data storage.

\section{References}

1. Derrington AM, Krauskopf J, Lennie P. Chromatic mechanisms in lateral geniculate nucleus of macaque. J Physiol. 1984; 357:241-265. [PubMed: 6512691]

2. Martin PR, Lee BB, White AJ, Solomon SG, Ruttiger L. Chromatic sensitivity of ganglion cells in the peripheral primate retina. Nature. 2001; 410:933-936. [PubMed: 11309618] 
3. Reid RC, Shapley RM. Space and time maps of cone photoreceptor signals in macaque lateral geniculate nucleus. J Neurosci. 2002; 22:6158-6175. [PubMed: 12122075]

4. Chatterjee S, Callaway EM. S cone contributions to the magnocellular visual pathway in macaque monkey. Neuron. 2002; 35:1135-1146. [PubMed: 12354402]

5. Dacey, DM. The Cognitive Neurosciences. Gazzaniga, MS., editor. MIT Press; Cambridge, MA: 2004. p. 281-301.

6. Sun H, Smithson HE, Zaidi Q, Lee BB. Specificity of cone inputs to macaque retinal ganglion cells. J Neurophysiol. 2006; 95:837-849. [PubMed: 16424455]

7. Buzas P, Blessing EM, Szmajda BA, Martin PR. Specificity of M and L cone inputs to receptive fields in the parvocellular pathway: random wiring with functional bias. J Neurosci. 2006; 26:11148-11161. [PubMed: 17065455]

8. Wiesel TN, Hubel DH. Spatial and chromatic interactions in the lateral geniculate body of the rhesus monkey. J Neurophysiol. 1966; 29:1115-1156. [PubMed: 4961644]

9. Jacobs GH, De Valois RL. Chromatic opponent cells in squirrel monkey lateral geniculate nucleus. Nature. 1965; 206:487-489. [PubMed: 4953498]

10. Chichilnisky EJ, Baylor DA. Receptive-field microstructure of blue-yellow ganglion cells in primate retina. Nat Neurosci. 1999; 2:889-893. [PubMed: 10491609]

11. Litke AM, et al. What does the eye tell the brain? Development of a system for the large scale recording of retinal output activity. IEEE Trans Nucl Sci. 2004; 51:1434-1440.

12. Frechette ES, et al. Fidelity of the ensemble code for visual motion in primate retina. $\mathrm{J}$ Neurophysiol. 2005; 94:119-135. [PubMed: 15625091]

13. Devries SH, Baylor DA. Mosaic arrangement of ganglion cell receptive fields in rabbit retina. $\mathbf{J}$ Neurophysiol. 1997; 78:2048-2060. [PubMed: 9325372]

14. Chichilnisky EJ, Kalmar RS. Functional asymmetries in ON and OFF ganglion cells of primate retina. J Neurosci. 2002; 22:2737-2747. [PubMed: 11923439]

15. Field GD, et al. Spatial properties and functional organization of small bistratified ganglion cells in primate retina. J Neurosci. 2007; 27:13261-13272. [PubMed: 18045920]

16. Wassle H, Peichl L, Boycott BB. Dendritic territories of cat retinal ganglion cells. Nature. 1981; 292:344-345. [PubMed: 7254331]

17. Dacey DM. The mosaic of midget ganglion cells in the human retina. J Neurosci. 1993; 13:53345355. [PubMed: 8254378]

18. Rodieck, RW. The first steps in seeing. Sinauer; Sunderland, MA: 1998.

19. Sincich LC, Zhang Y, Tiruveedhula P, Horton JC, Roorda A. Resolving single cone inputs to visual receptive fields. Nat Neurosci. 2009; 12:967-969. [PubMed: 19561602]

20. Baylor DA, Nunn BJ, Schnapf JL. Spectral sensitivity of cones of the monkey Macaca fascicularis. J Physiol. 1987; 390:145-160. [PubMed: 3443931]

21. Roorda A, Williams DR. The arrangement of the three cone classes in the living human eye. Nature. 1999; 397:520-522. [PubMed: 10028967]

22. Lee BB, Martin PR, Valberg A. The physiological basis of heterochromatic flicker photometry demonstrated in the ganglion cells of the macaque retina. J Physiol. 1988; 404:323-347. [PubMed: 3253435]

23. Kaiser PK, Lee BB, Martin PR, Valberg A. The physiological basis of the minimally distinct border demonstrated in the ganglion cells of the macaque retina. J Physiol. 1990; 422:153-183. [PubMed: 2352178]

24. Lee BB, Pokorny J, Smith VC, Kremers J. Responses to pulses and sinusoids in macaque ganglion cells. Vision Res. 1994; 34:3081-3096. [PubMed: 7975341]

25. Klug K, Herr S, Ngo IT, Sterling P, Schein S. Macaque retina contains an S-cone OFF midget pathway. J Neurosci. 2003; 23:9881-9887. [PubMed: 14586017]

26. Tailby C, Szmajda BA, Buzas P, Lee BB, Martin PR. Transmission of blue (S) cone signals through the primate lateral geniculate nucleus. J Physiol. 2008; 586:5947-5967. [PubMed: 18955378]

27. Lee SC, Grunert U. Connections of diffuse bipolar cells in primate retina are biased against Scones. J Comp Neurol. 2007; 502:126-140. [PubMed: 17335043] 
28. Solomon SG, Lee BB, White AJ, Ruttiger L, Martin PR. Chromatic organization of ganglion cell receptive fields in the peripheral retina. J Neurosci. 2005; 25:4527-4539. [PubMed: 15872100]

29. De Valois RL, Abramov I, Jacobs GH. Analysis of response patterns of LGN cells. J Opt Soc Am. 1966; 56:966-977. [PubMed: 4959282]

30. de Monasterio FM, Gouras P, Tolhurst DJ. Trichromatic colour opponency in ganglion cells of the rhesus monkey retina. J Physiol. 1975; 251:197-216. [PubMed: 810577]

31. Lee BB. Receptive field structure in the primate retina. Vision Res. 1996; 36:631-644. [PubMed: 8762295]

32. Dacey DM. Parallel pathways for spectral coding in primate retina. Annu Rev Neurosci. 2000; 23:743-775. [PubMed: 10845080]

33. Gegenfurtner KR. Cortical mechanisms of colour vision. Nat Rev Neurosci. 2003; 4:563-572. [PubMed: 12838331]

34. Solomon SG, Lennie P. The machinery of colour vision. Nat Rev Neurosci. 2007; 8:276-286. [PubMed: 17375040]

35. Calkins DJ, Schein SJ, Tsukamoto Y, Sterling P. M and L cones in macaque fovea connect to midget ganglion cells by different numbers of excitatory synapses. Nature. 1994; 371:70-72. [PubMed: 8072528]

36. Jusuf PR, Martin PR, Grunert U. Random wiring in the midget pathway of primate retina. J Neurosci. 2006; 26:3908-3917. [PubMed: 16611806]

37. Ghosh KK, Goodchild AK, Sefton AE, Martin PR. Morphology of retinal ganglion cells in a new world monkey, the marmoset Callithrix jacchus. J Comp Neurol. 1996; 366:76-92. [PubMed: 8866847]

38. Lennie, P.; Haake, W.; Williams, DR. Computational models of visual processing. Landy, M.; Movshon, JA., editors. MIT Press; 1991. p. 71-82.

39. Reid RC, Shapley RM. Spatial structure of cone inputs to receptive fields in primate lateral geniculate nucleus. Nature. 1992; 356:716-718. [PubMed: 1570016]

40. Diller $\mathrm{L}$, et al. $\mathrm{L}$ and $\mathrm{M}$ cone contributions to the midget and parasol ganglion cell receptive fields of macaque monkey retina. J Neurosci. 2004; 24:1079-1088. [PubMed: 14762126]

41. Hofer H, Carroll J, Neitz J, Neitz M, Williams DR. Organization of the human trichromatic cone mosaic. J Neurosci. 2005; 25:9669-9679. [PubMed: 16237171]

42. Packer OS, Williams DR, Bensinger DG. Photopigment transmittance imaging of the primate photoreceptor mosaic. J Neurosci. 1996; 16:2251-2260. [PubMed: 8601805]

43. Nathans J. The evolution and physiology of human color vision: insights from molecular genetic studies of visual pigments. Neuron. 1999; 24:299-312. [PubMed: 10571225]

44. Calkins DJ, Sterling P. Evidence that circuits for spatial and color vision segregate at the first retinal synapse. Neuron. 1999; 24:313-321. [PubMed: 10571226]

45. Kouyama N, Marshak DW. Bipolar cells specific for blue cones in the macaque retina. J Neurosci. 1992; 12:1233-1252. [PubMed: 1556594]

46. Dacey DM, Lee BB. The 'blue-on' opponent pathway in primate retina originates from a distinct bistratified ganglion cell type. Nature. 1994; 367:731-735. [PubMed: 8107868]

47. Wassle H, Grunert U, Martin PR, Boycott BB. Immunocytochemical characterization and spatial distribution of midget bipolar cells in the macaque monkey retina. Vision Res. 1994; 34:561-579. [PubMed: 8160377]

48. Wachtler T, Doi E, Lee T, Sejnowski TJ. Cone selectivity derived from the responses of the retinal cone mosaic to natural scenes. J Vis. 2007; 7:6. [PubMed: 17685813]

49. Hosoya T, Baccus SA, Meister M. Dynamic predictive coding by the retina. Nature. 2005; 436:7177. [PubMed: 16001064]

50. Neitz J, Carroll J, Yamauchi Y, Neitz M, Williams DR. Color perception is mediated by a plastic neural mechanism that is adjustable in adults. Neuron. 2002; 35:783-792. [PubMed: 12194876] 


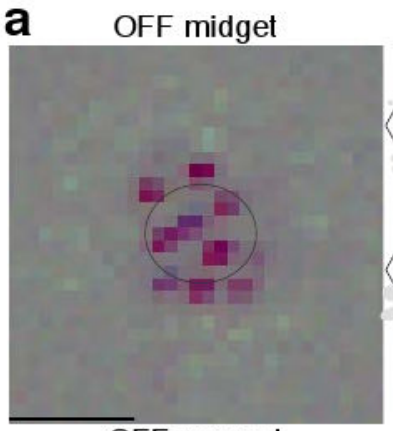

OFF parasol

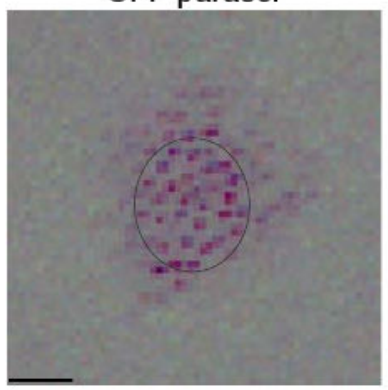

b ON midget

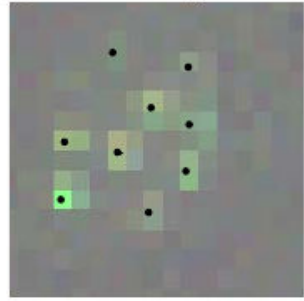

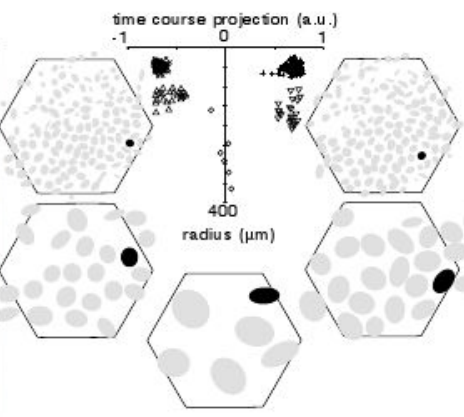

small bistratified

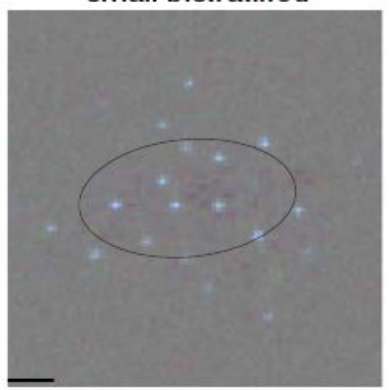

ON parasol

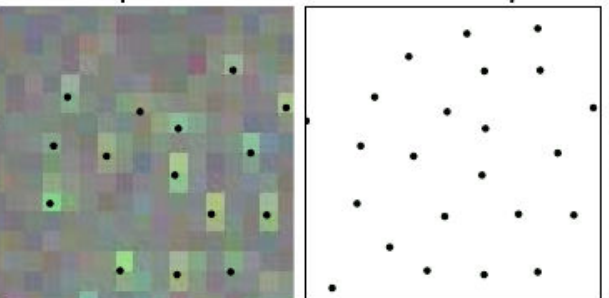

ON midget

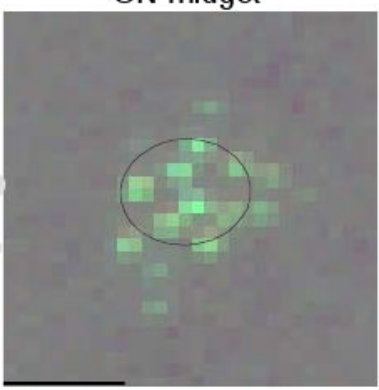

ON parasol

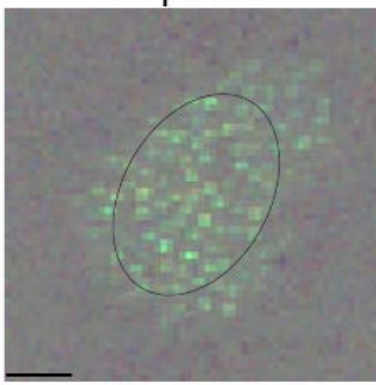

alignment

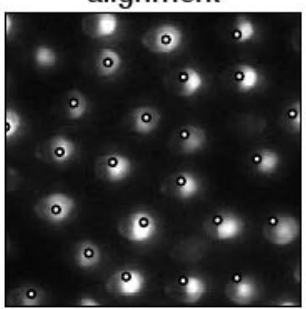

Figure 1.

Cell type classification and RFs at single cone resolution. (a) RFs of 323 RGCs recorded simultaneously from isolated macaque retina were measured using reverse correlation with white noise stimuli. Central panel: RF radius vs. first principal component of response time course; clusters reveal distinct cell types. Surrounding panels: Gaussian fits to RFs of cells from each cluster, superimposed on electrode array outline. Outer panels: fine-grained spatial RF profiles for highlighted cells. Scale bars: $60 \mu \mathrm{m}$. (b) First and second panels show spatial RF profiles of two cells, with putative locations of cones (black dots) identified by thresholding. Third panel shows the putative cone map accumulated across cells. Fourth panel shows putative cone map overlaid on a photograph of cone outer segments labeled with peanut agglutinin. 

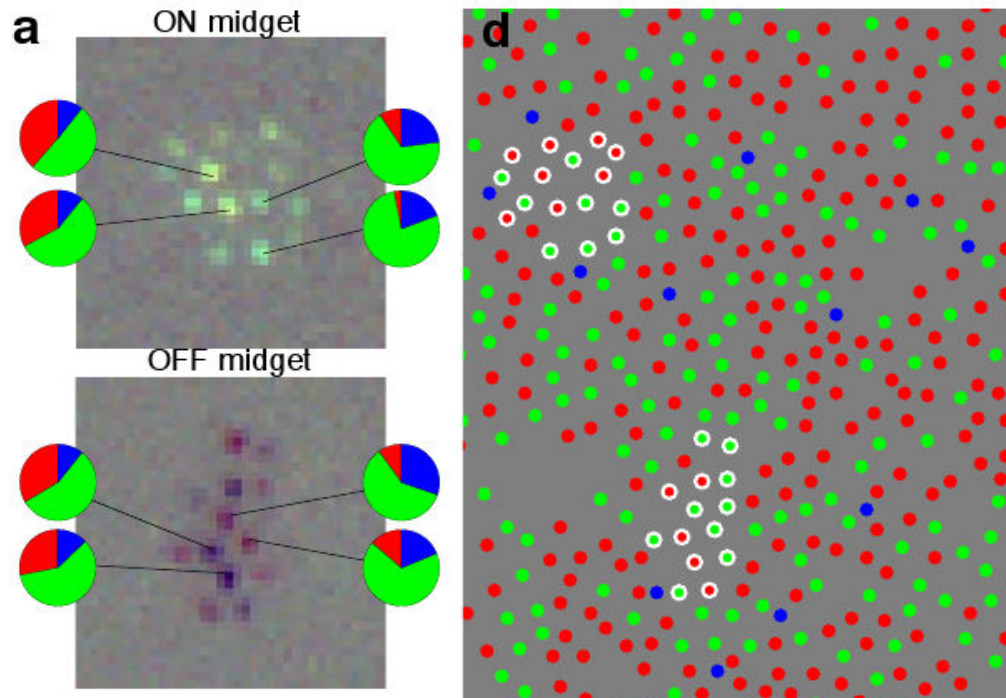

b
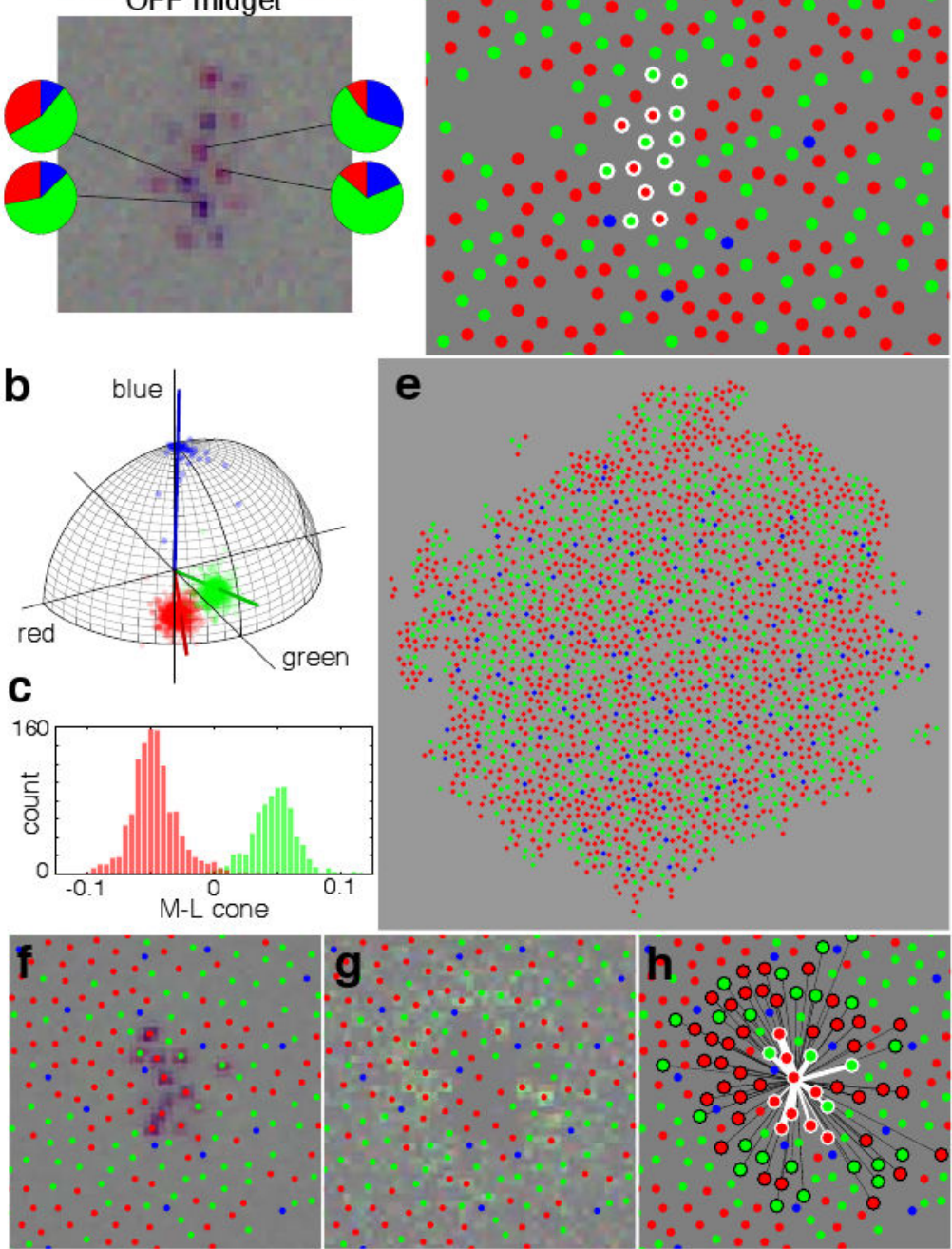

Figure 2.

Cone type identification and inputs to RGCs. (a) The spectral sensitivity of cones providing input to two cells is represented by the relative magnitude of the red, green and blue STA values at their locations. (b) For every cone in one recording, these values are shown as points on a sphere. Colored lines indicate spectral sensitivity of macaque cones. Point color indicates classification as L (red), M (green), or S (blue). (c) L/M cone discriminability quantified by projection along the line joining $\mathrm{L}$ and $\mathrm{M}$ loci. Bars color indicates classification. S cones excluded. (d) Assembled cone mosaic from all RGCs over a region. Cones from (a) are circled. (e) Full mosaic of 2,373 cones from one recording. (f) Cone 
mosaic overlaid on STA, revealing strength of cone inputs. (g) Weaker cone inputs in RF surround revealed by truncating positive values and renormalizing. (h) Connectivity diagram, with line thickness proportional to strength of each cone input. Surround (black) line thicknesses were increased five-fold relative to center (white) line thicknesses for visibility. 
a

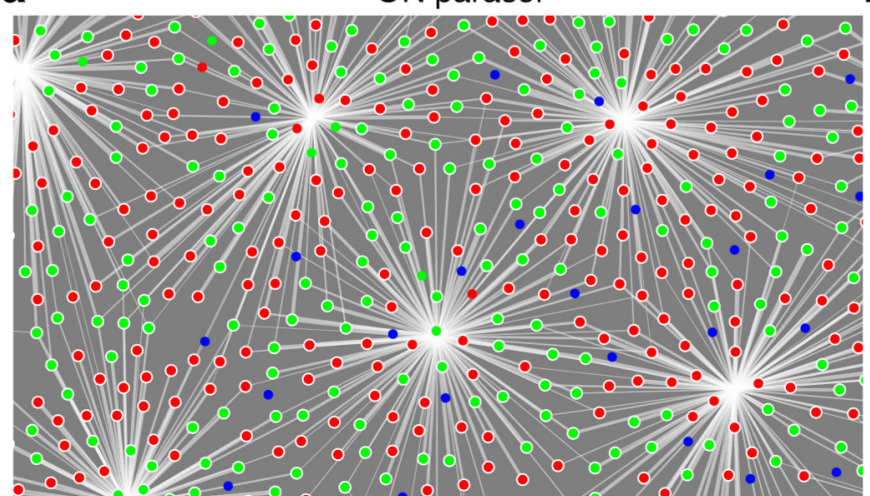

C

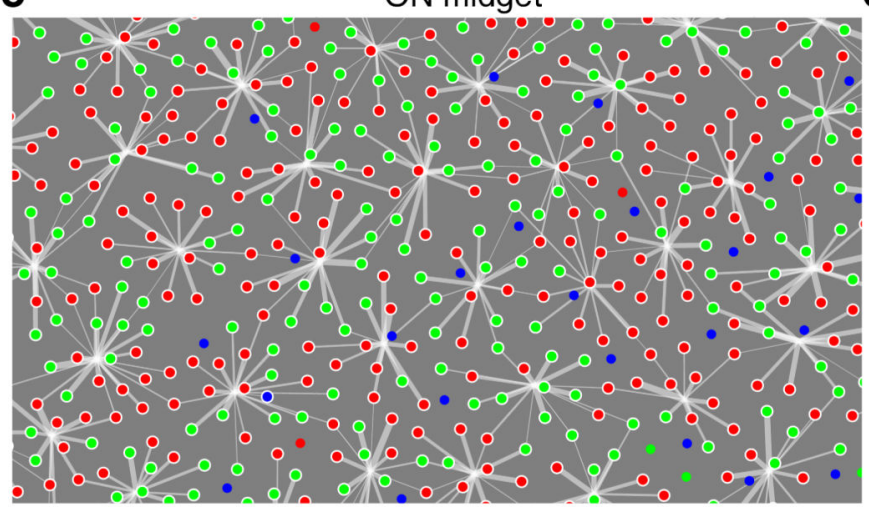

b

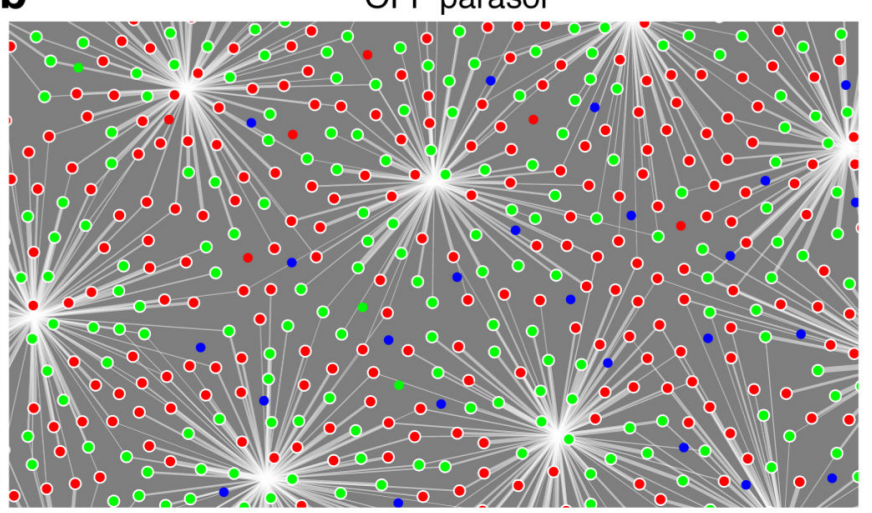

d

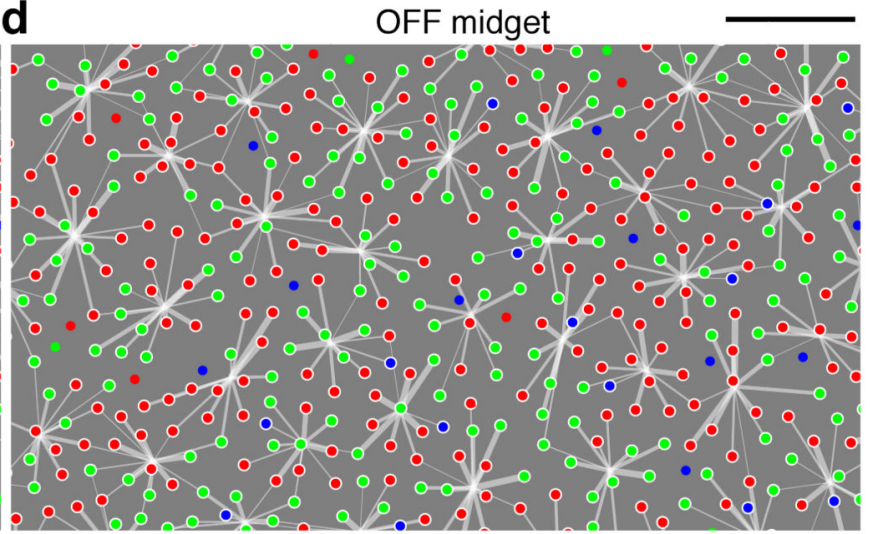

Figure 3.

Full functional sampling of cone lattice by four RGC types. Each panel shows cones identified in a single recording (red, green and blue dots) sampled by RF centers of RGCs of a single type. Cones are identical in all panels. Cones providing input to at least one RGC are highlighted with an annulus. Scale bar: $50 \mu \mathrm{m}$. 

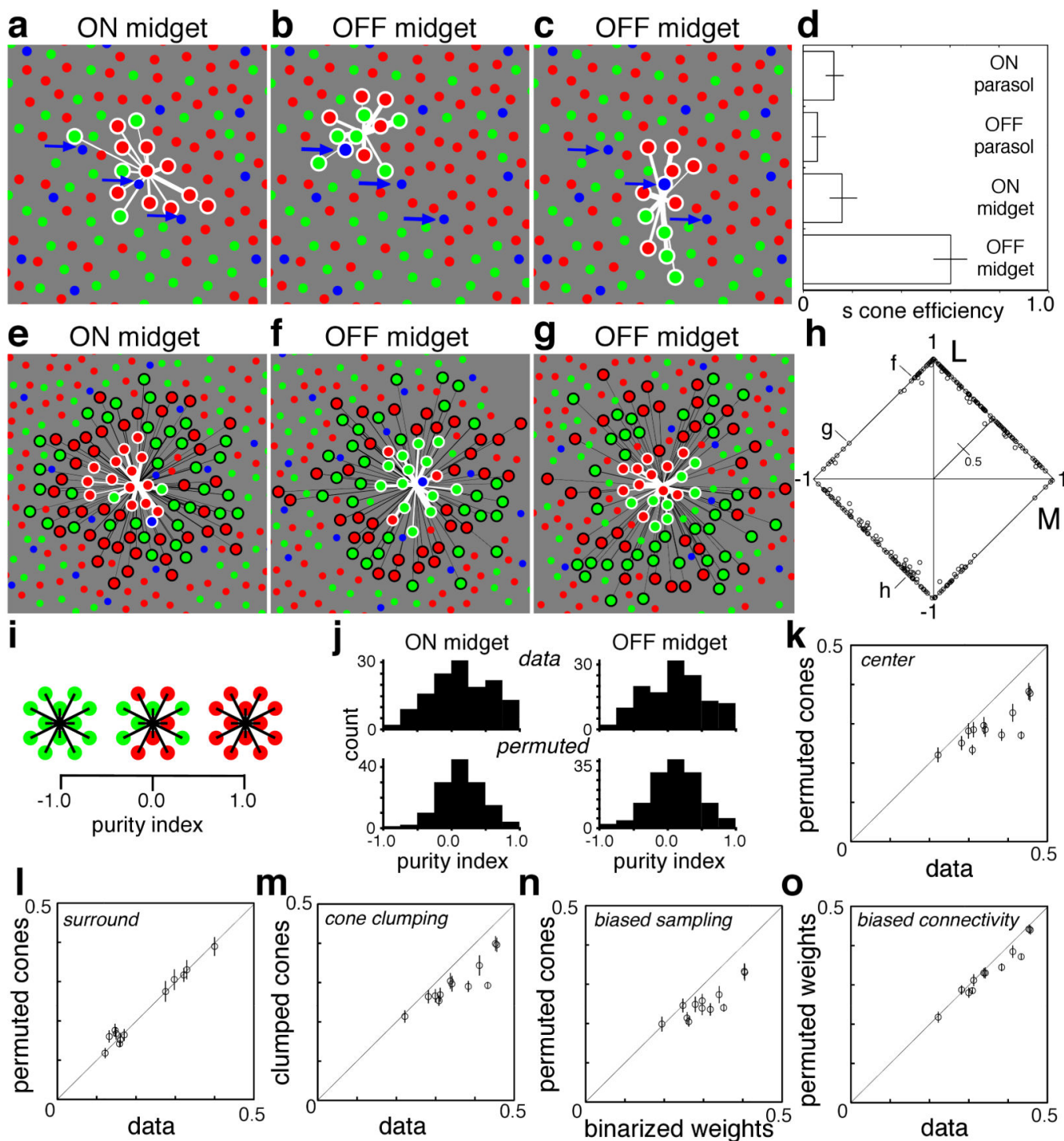

Figure 4.

Cone type specificity. (a) ON midget cell lacking input from nearby $\mathrm{S}$ cones (arrows). (b,c) OFF midget cells receiving input from these cones. (d) Frequency of strong $\mathrm{S}$ cone sampling by each cell type. (f,g) Two midget cells with relatively pure L/M cone input. (h) Midget cell with mixed L/M input. (e) Normalized L,M,S cone inputs to all midget cells in one recording, obtained with cone-isolating stimuli. Abscissa: $\mathrm{M} /(|\mathrm{L}|+|\mathrm{M}|+|\mathrm{S}|)$, ordinate: $\mathrm{L} /(|\mathrm{L}|+\mid$ $\mathrm{M}|+| \mathrm{S} \mid$ ). Diagonals: no S cone input. Upper-right and lower-left quadrants: same-sign (nonopponent) L/M input. Lower-right and upper-left quadrants: opposite-sign (opponent) L/M input. Letters: cells from previous panels. (i) Purity index schematic. (j) (Top) Purity index for ON and OFF midget cells in one recording; width (SD) 0.45, 0.44 respectively. (Bottom) Purity index after random permutation of $\mathrm{L} / \mathrm{M}$ cones; width $0.37 \pm 0.04,0.36 \pm 0.04$ respectively (mean $\pm 2 \mathrm{SD}$ across permutations). (k) Comparison of purity distribution width in data and permutations. Each point represents $>50$ simultaneously recorded ON or OFF midget cells. Error bars: 1 SD across permutations. (l) As (k), using cones from RF 
surround. (m) Using random cone mosaics with clumping matched to data. (n) Using binarized cone weights $(0,1)$. (o) Using random permutation of cone weights in RF center. 